\title{
The Mantle Dynamics, the Crustal Formation, and the Hydrothermal Activity of the Southern Mariana Trough Back-Arc Basin
}

\author{
Nobukazu Seama, Hiroshi Sato, Yoshifumi Nogi, and Kyoko Okino
}

\begin{abstract}
The Southern Mariana Trough back-arc basin is a currently active back arc basin, and it has fast spreading morphologic and geophysical characteristics, suggesting an additional magma supply, even though the full spreading rate is categorized as slow spreading. Five hydrothermal vent sites have been found within $5 \mathrm{~km}$ around the spreading axis at $13^{\circ} \mathrm{N}$. The Japanese TAIGA Project selected this area as one of three integrated target sites, and TAIGA Project members conducted series of JAMSTEC research cruises for different types of geophysical surveys, together with dive observation and samplings by the submersible Shinkai 6500. We reviewed the results from these geophysical surveys and the volcanic rock samples to summarize the products from the TAIGA Project. The results provide strong constraints on the mantle dynamics and the crustal formation at the Southern Mariana Trough back-arc basin; all the results support that they are influenced by hydration derived from the subducting slab with accompanying the additional magma supply. Furthermore, the results from the geophysical and geological surveys for the five hydrothermal vent sites provide characteristic features on the hydrothermal activity and the features are different between on-axis and off-axis hydrothermal sites. The on-axis hydrothermal site is associated with an episodic diking event followed by fissures in a fourth order ridge segment, and its duration and size vary depending on the episodic diking event and on the fissures following. In contrast, the formation of the off-axis hydrothermal sites is closely related to the residual heat from the volcanism rather than tectonic stresses accompanied by faults, and the off-axis hydrothermal activity is for a long period and in a large scale. We summarized all the evidence to propose our scenario of the mantle dynamics, the crustal formation, and the hydrothermal activity of the Southern Mariana Trough back-arc basin.
\end{abstract}

\section{N. Seama $(\bowtie)$}

Department of Earth and Planetary Sciences,

Kobe University, 1-1 Rokkodai, Nada, Kobe 657-8501, Japan

e-mail: seama@kobe-u.ac.jp

H. Sato

School of Business Administration, Senshu University,

2-1-1 Higashimita Tama, Kawasaki, Kanagawa 214-8580, Japan

Y. Nogi

National Institute of Polar Research, The Graduate University

for Advanced Studies (Sokendai), 10-3 Midoricho, Tachikawa,

Tokyo 190-8518, Japan

K. Okino

Atmosphere and Ocean Research Institute, The University of Tokyo,

5-1-5 Kashiwanoha, Kashiwa, Chiba 277-8564, Japan 


\section{Keywords}

Back-arc basin - Crustal structure - Hydrothermal activity - Mantle structure - Seafloor spreading $\bullet$ Seismicity

\subsection{Introduction}

The Mariana Trough back-arc basin is a currently active back-arc basin, where the old Pacific Plate is subducting (Fig. 17.1). The spreading rates of the Mariana Trough back-arc basin increase from the north to the south. Studies of the geomagnetic anomalies using the Matuyama-Brunhes boundary $(0.78 \mathrm{Ma})$ reported the full spreading rates of $10 \mathrm{~km} / \mathrm{Myr}$ at $22^{\circ} \mathrm{N}$ in the northern end (Yamazaki et al. 2003) and of $\sim 64 \mathrm{~km} / \mathrm{Myr}$ in maximum at $13^{\circ} \mathrm{N}$ in the southern end (Martinez et al. 2000). Repeated GPS surveys in the Mariana Islands show similar trend of the full spreading rates; that is $15.9 \pm 6.6 \mathrm{~km} / \mathrm{Myr}$ at $18.7^{\circ} \mathrm{N}$ and $44.6 \pm 2.7 \mathrm{~km} / \mathrm{Myr}$ at $13.6^{\circ} \mathrm{N}$ (Kato et al. 2003). The shape of the subducting slab (Gudmundsson and Sambridge 1998) varies in the subducting angle and strike. The subducting slab is located mostly beneath the active Mariana Island Arc, except for the northern and southern ends where it is located beneath the spreading axes.

The seafloor spreading features also vary from the north to the south, and the Southern Mariana Trough back-arc basin has fast spreading morphologic and geophysical
Fig. 17.1 Bathymetry map of the southern Mariana Trough back-arc basin (top right) with its location shown by the square in the regional map (top left). The triangles indicate the locations of the OBEM observations for the marine MT survey. The spreading axis (arrows), depth contours to the surface of the subducting slab (thin solid lines with their depth in $\mathrm{km}$ ) inferred from a seismic research (Gudmundsson and Sambridge 1998), and the location of the bottom map (square) are also shown. Five hydrothermal vent sites (stars with their names) shown in bathymetry map (bottom). The square by solid lines, the square by broken lines, and the ellipse indicate the seismic reflection/ refraction survey area, the MMR survey area, and the area of the near-bottom acoustic and geomagnetic mapping using the AUV Urashima, respectively
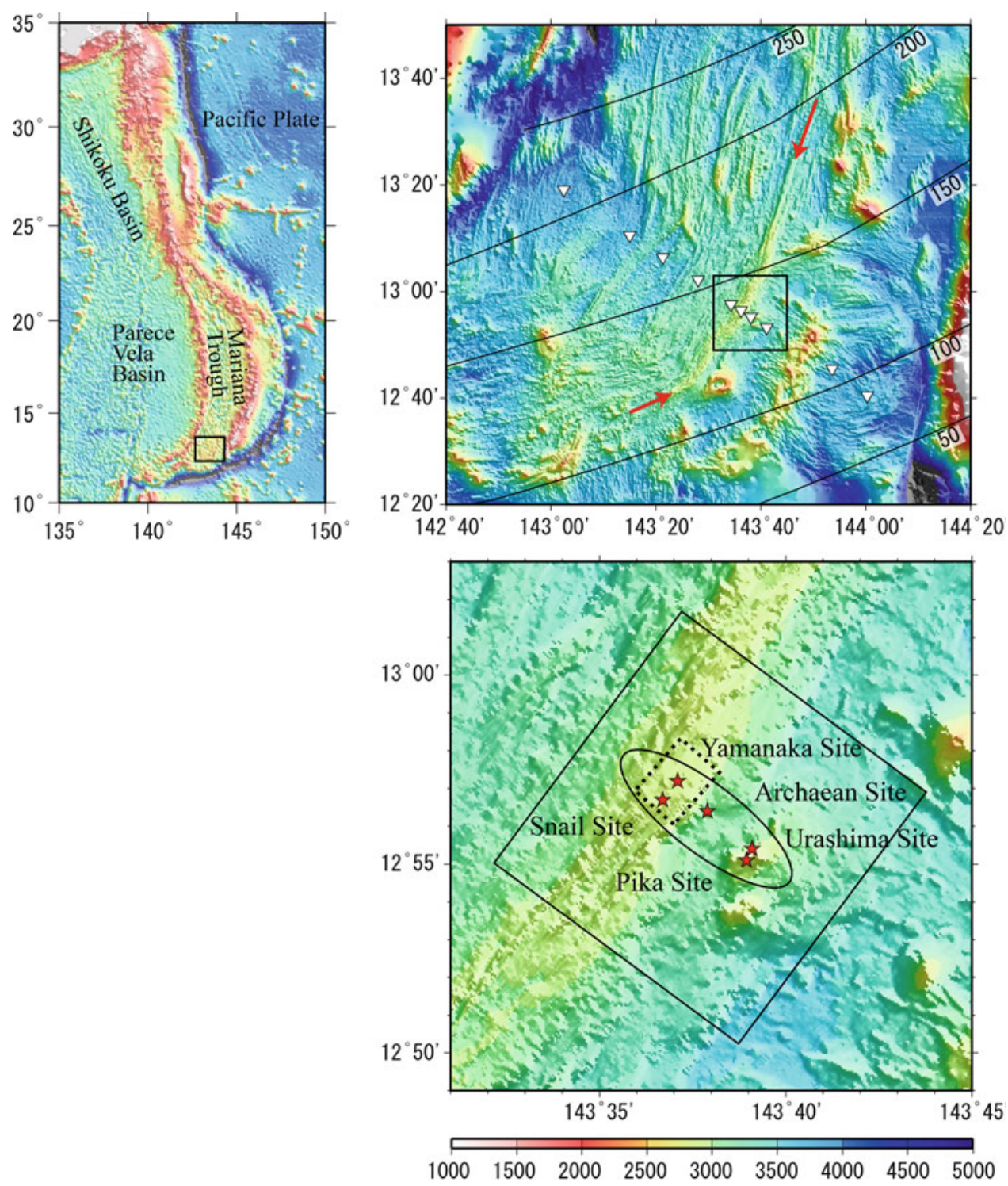
characteristics that are unlike the features of the basin to the north (Martinez et al. 2000). The morphology of the spreading axis of the Southern Mariana Trough back-arc basin shows an axial relief with a broad, smooth cross section, and lacks a deep central graben (Martinez et al. 2000). Kitada et al. (2006) have compiled extensive gravity and bathymetry data for the whole Mariana Trough, and they estimated crustal thickness variation along the spreading axis using the Mantle Bouguer anomalies (MBA), which were calculated by subtracting the predictable gravity signal due to the seawater/crust and crust/mantle density boundaries. Their results show that the two segments in the Southern Mariana Trough (south of $14^{\circ} 22^{\prime} \mathrm{N}$ ) have two characteristic features compared to the other segments in the Mariana Trough; larger individual crustal thickness averages $(5.9-6.9 \mathrm{~km})$ and smaller normalized variations in crustal thickness $(28-30 \mathrm{~m} / \mathrm{km})$. They interpreted these characteristic features as the existence of a sheet-like mantle upwelling with a relatively higher magmatic activity under the spreading axis, suggesting that the spreading process of the Southern Mariana Trough is similar to that of a fast spreading ridge. Becker et al. (2010) conducted a sixchannel seismic reflection survey, which consisted of east-west transects spaced 5 nautical miles $(9.26 \mathrm{~km})$ apart and oblique $\left(\sim 65^{\circ}\right)$ to the strike of the spreading axis. The seismic reflection data show a magma chamber reflector beneath the southernmost segment of the spreading axis in the Mariana Trough, although it appears only in a single line despite 12 crossings of the ridge axis. They identified a magma chamber at $1.5 \mathrm{~s}$ two-way travel time below the crest of the ridge. All these morphologic and geophysical features of the Southern Mariana Trough back-arc basin show fast spreading characteristics, suggesting the additional magma supply, even though the full spreading rate of 45-64 km/Myr is categorized as slow spreading.

A plume survey using standard conductivity-temperaturedepth-optical tow-yos between $12^{\circ} 41^{\prime} \mathrm{N}$ and $13^{\circ} 13^{\prime} \mathrm{N}$ followed the spreading axes as closely as possible in the Southern Mariana Trough back-arc basin (Baker et al. 2005). Their results show distinct hydrothermal anomalies over six areas, and they found multiple plumes overlying $19 \%$ of the total length of the survey section that is a coverage comparable to mid-ocean ridges spreading at similar rates. The biggest plume anomaly locates between $12^{\circ} 55^{\prime} \mathrm{N}$ and $12^{\circ} 58 \mathrm{~N}$, and five hydrothermal vent sites have been found within $5 \mathrm{~km}$ in the area (Urabe et al. 2004; Nakamura et al. 2013); two sites on the spreading axis, one site at the eastern foot of the axial high, and two sites on an off-axis knoll.

The Japanese TAIGA Project (Urabe, Chap. 1) selected the Southern Mariana Trough back-arc basin including five hydrothermal vent sites as one of three integrated target sites. TAIGA Project members conducted series of JAMSTEC research cruises for different types of geophysical surveys, together with dive observations and samplings by the submersible Shinkai 6500. Furthermore, they conducted a cruise for a Benthic Multicoring System (BMS) to sample the volcanic rock cores. The geophysical surveys consist of (1) surface geophysical surveys, (2) a marine magnetotelluric (MT) survey of a $120 \mathrm{~km}$ long transect across the spreading axis using 10 ocean bottom electro-magnetometers (OBEM), (3) a $15 \mathrm{~km}$ scale seismic reflection/refraction survey and seismicity observation using nine ocean bottom seismometers (OBS), (4) a magnetometric resistivity (MMR) survey around the on-axis hydrothermal vent sites, and (5) near-bottom acoustic and geomagnetic mapping around the five hydrothermal vent sites using the autonomous underwater vehicle (AUV) Urashima. In this paper, we review results from the geophysical surveys and the volcanic rock samples in the Southern Mariana Trough back-arc basin to summarize the products of the TAIGA Project.

\subsection{Asymmetric Seafloor Spreading}

A series of JAMSTEC research cruises allowed us to obtain bathymetry and geomagnetic field data in the Southern Mariana Trough back-arc basin. Seama and Okino (Chap. 20) analyzed these data to derive two main features; (1) the seafloor spreading shows high asymmetry and (2) the asymmetric seafloor spreading has two different styles between two ridge segments (we call the northern segment and the southern segment here after, and their locations are shown in Fig. 17.2). The highly asymmetric seafloor spreading is recognized as much faster spreading in the west side of the spreading axis compared to the east side. They estimated the spreading rate of the southern segment as $46 \mathrm{~km} / \mathrm{Myr}$ with its half rate of $33 \mathrm{~km} / \mathrm{Myr}$ for the west side and $13 \mathrm{~km} /$ Myr for the east side. The full rate of $46 \mathrm{~km} / \mathrm{Myr}$ is consistent with the present full spreading rate of $44.6 \pm 2.7 \mathrm{~km} /$ Myr at $13.6^{\circ} \mathrm{N}$ based on the repeated GPS surveys (Kato et al. 2003).

The asymmetric seafloor spreading has two different styles between the northern segment and the southern segment. Seama and Okino (Chap. 20) proposed that the northern segment is accompanied by an obvious trace of a ridge jump to the east (trench side), while the southern segment is not. The obvious trace of the ridge jump is supported by the bathymetry profiles across the spreading axis, the MBA based on Kitada et al. (2006), and the distribution of the crustal magnetization derived from the total intensity of the geomagnetic anomaly field data (Fig. 17.2). The location of the failed spreading axis due to the ridge jump is suggested at the local symmetry axis in the bathymetry profiles because this local symmetry axis is similar in the bathymetric feature to a spreading axis. This location coincides with the center of the bull's eye feature in the MBA, which is often found 
Fig. 17.2 Present spreading axis (solid lines), failed spreading axis (thick broken lines), and non-transform offset traces determined from seafloor morphology (thin broken lines) shown in the bathymetry map (top), the Mantle Bouguer anomaly map (middle), and the distribution of the crustal magnetization derived from the total geomagnetic anomaly field data (bottom). In the bottom figure, the identifications of the geomagnetic anomaly lineations (green lines with its geomagnetic anomaly number) and bathymetry contours of 3,000 m depth (dots) are also shown. After Seama and Okino (Chap. 20)
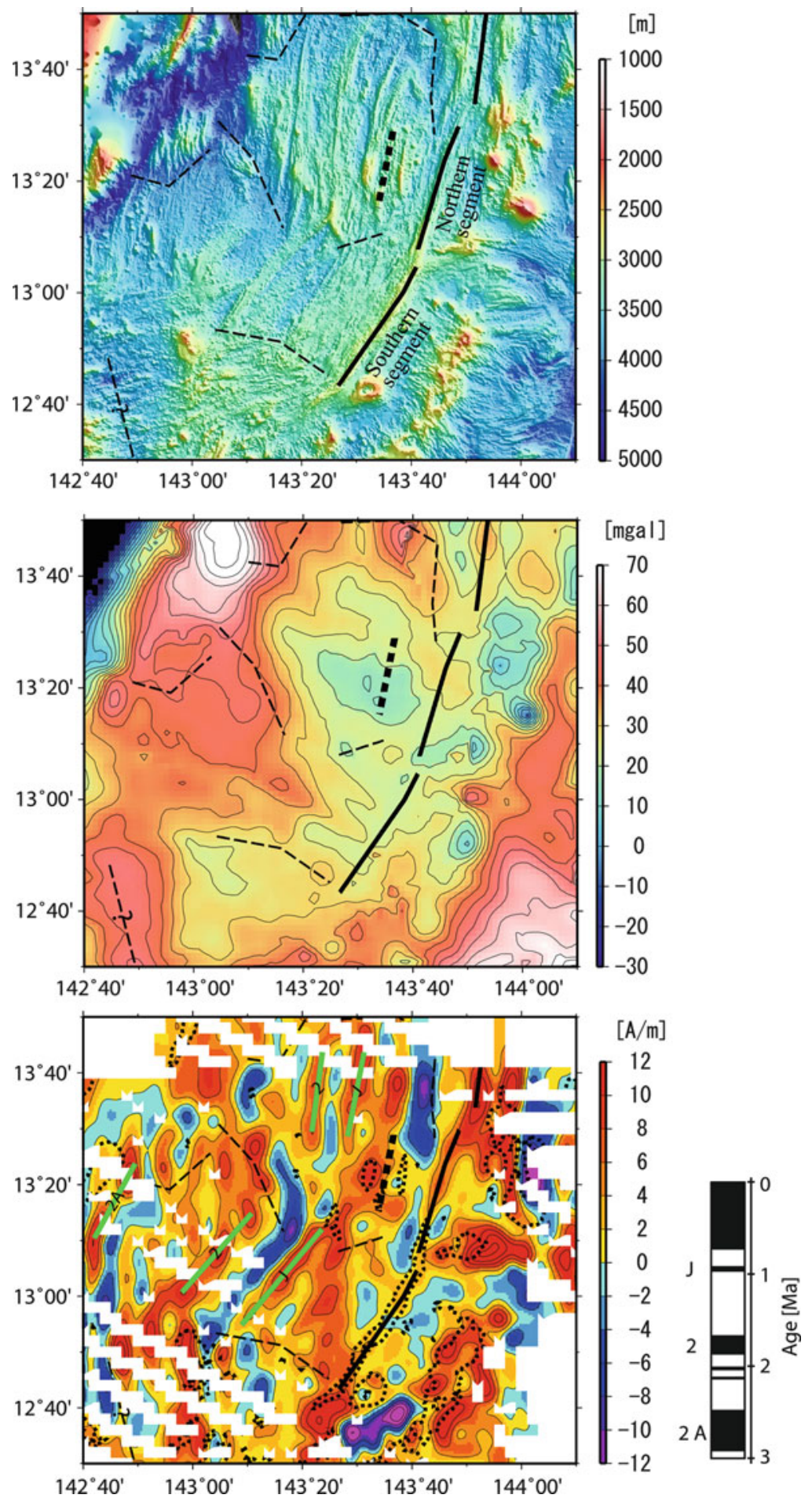

at ridge segments of slow spreading axes (e.g. Lin et al. 1990). The crustal magnetization distribution also supports the ridge jump because it can explain the existence of the negative magnetization lineation between the present and the failed spreading axes. They interpreted that the negative magnetization lineation is Matuyama Chron (before $0.78 \mathrm{Ma}$ ) made by the failed spreading axis in its east side and that the ridge jump occurred during the Brunhes Chron. If the negative magnetization lineation would be made by the present spreading axis without the ridge jump, the half spreading rate would be $5 \mathrm{~km} / \mathrm{Myr}$ in maximum (the distance from the present spreading axis to the Matuyama-Brunhes boundary is $4 \mathrm{~km}$ in maximum), which is too slow spreading rate to be consistent with other data. The ridge jump leads to the apparent asymmetric seafloor spreading of the northern segment. In contrast, the southern segment shows the asymmetric seafloor spreading without accompanied by an obvious trace of a ridge jump. 


\subsection{Upper Mantle Structure}

Marine magnetotelluric (MT) survey is one of tools to derive upper mantle structure beneath the ocean bottom. Shindo et al. (2012) carried out an electromagnetic experiment with 10 OBEM along a $\sim 120 \mathrm{~km}$ long profile across the spreading axis to estimate an electrical resistivity structure, and hence the physical property like temperature, water and melt contents in the upper mantle. The MT method is a base for the OBEM data analysis. In the MT method, magnetic and electric field data observed simultaneously by the OBEM were used to derive the MT responses, which is a transfer function from the magnetic field to the electric field variation in the frequency domain. Then, they corrected seafloor topographic distortions in the MT responses. Finally, a minimum electrical resistivity structure beneath the observation sites was estimated to fit the processed MT responses by performing a smooth model inversion analysis.

A preliminary result of two-dimensional upper mantle electrical resistivity structure from this MT analysis (Fig. 17.3), shows high asymmetry about the spreading axis. The trenchward side shows high resistivity $(\sim 300 \mathrm{Ohm}-\mathrm{m})$ at all depths, while the opposite side (the west side) shows that a high resistivity layer $(>300 \mathrm{Ohm}-\mathrm{m})$ with $\sim 40 \mathrm{~km}$ thick is underlain by a low resistivity $(\sim 10 \mathrm{Ohm}-\mathrm{m})$ region. The region under the spreading axis has intermediate resistivity ( 100 Ohm-m), which is connected to the low resistivity region in the west side. The subducting slab is well imaged as the higher resistivity region in the trenchward side, which is consistent with the surface of the subducting slab (the black broken line in Fig. 17.3) inferred from a seismic research (Gudmundsson and Sambridge 1998). But it is not imaged in the west side; it is probably because the thick low resistivity region in the shallower depth limits the resolution for the high resistivity region beneath it. The low resistivity region in the west side, which may be connected to the intermediate resistivity region under the spreading axis, is probably influenced by hydration driven by water release from the subducting slab. The uppermost high resistivity layer in the west side is interpreted as a dry lithosphere formed at the spreading axis. The high resistivity region in the trenchward side may result from a cold nose in the mantle wedge where is low temperature as well as the absence of a significant amount of water.

\subsection{Crustal Structure}

Crustal structure was investigated using a refraction survey. Sato et al. (Chap. 18) conducted a seismic refraction survey using OBS in the southern segment of the spreading axis in the Mariana Trough back-arc basin. The data analysis allows them to derive a 3-D seismic velocity structure,

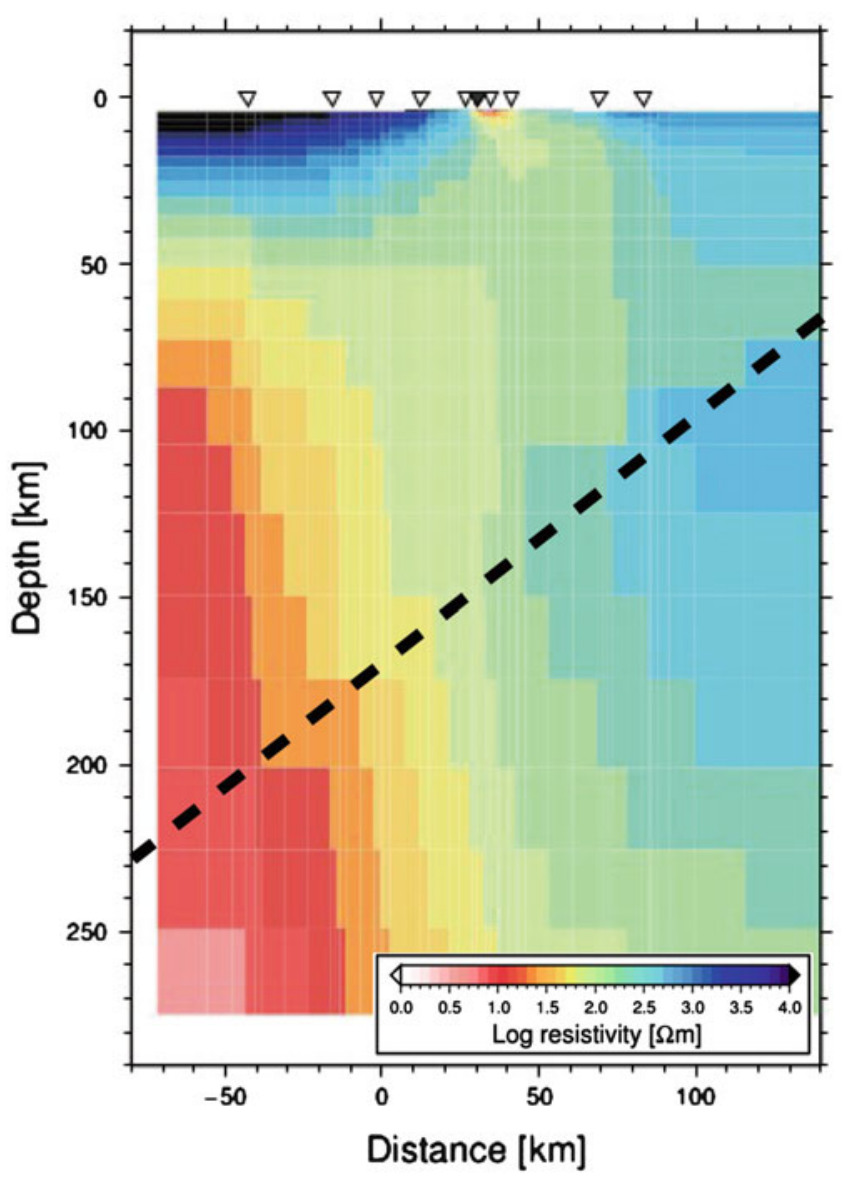

Fig. 17.3 Two-dimensional upper mantle electrical resistivity structure obtained from the marine MT analysis. The locations of the OBEM observations are shown by the triangles at the top, and the triangle is filled for the location on the spreading axis. The black broken line indicates the surface of subducting slab inferred from a seismic research (Gudmundsson and Sambridge 1998). The location of the OBEM in a map view is shown in Fig. 17.1

which indicate three characteristic features (Fig. 17.4); (1) a low-velocity structure just beneath the spreading axis, (2) a high-velocity structure with convex upward beneath an off-axis knoll, and (3) a relatively thicker layer 2 (about $3 \mathrm{~km}$ ) with lower seismic velocities over the refraction survey area compared with normal mid-ocean ridges. The low seismic velocity structure just beneath the spreading axis suggests that the area beneath the axis is hotter due to magmatic activity. As the seismic reflection profile of Becker et al. (2010) shows no magma chamber reflector in their study area, the low-velocity zone is probably not a magma chamber with abundant melt, but a warm zone with a chamber of crystal-rich mush. Further, the low-velocity zone aligns with the third-order ridge segment that is defined by the bathymetry. These results suggest that sheetlike mantle upwellings beneath the first-order ridge segment on the basis of gravity data (Kitada et al. 2006) can be subdivided into upwellings beneath the third-order ridge segment. 
Fig. 17.4 One-dimensional (top) and three-dimensional (bottom right) crustal velocity structure from the seismic refraction analysis (Sato et al. Chap. 18). The three-dimensional crustal velocity structure is shown in map views with depth (z) from the sea surface. Locations of the five hydrothermal vent sites (stars), OBS (red circles and triangles), and airgun survey profiles (black lines) are also shown in the bathymetry map (bottom left). The broken lines and the red arrows indicate third-order ridge segments and the area of the layer 3 thickening beneath the off-axis knoll, respectively. The location of the survey area is shown in Fig. 17.1
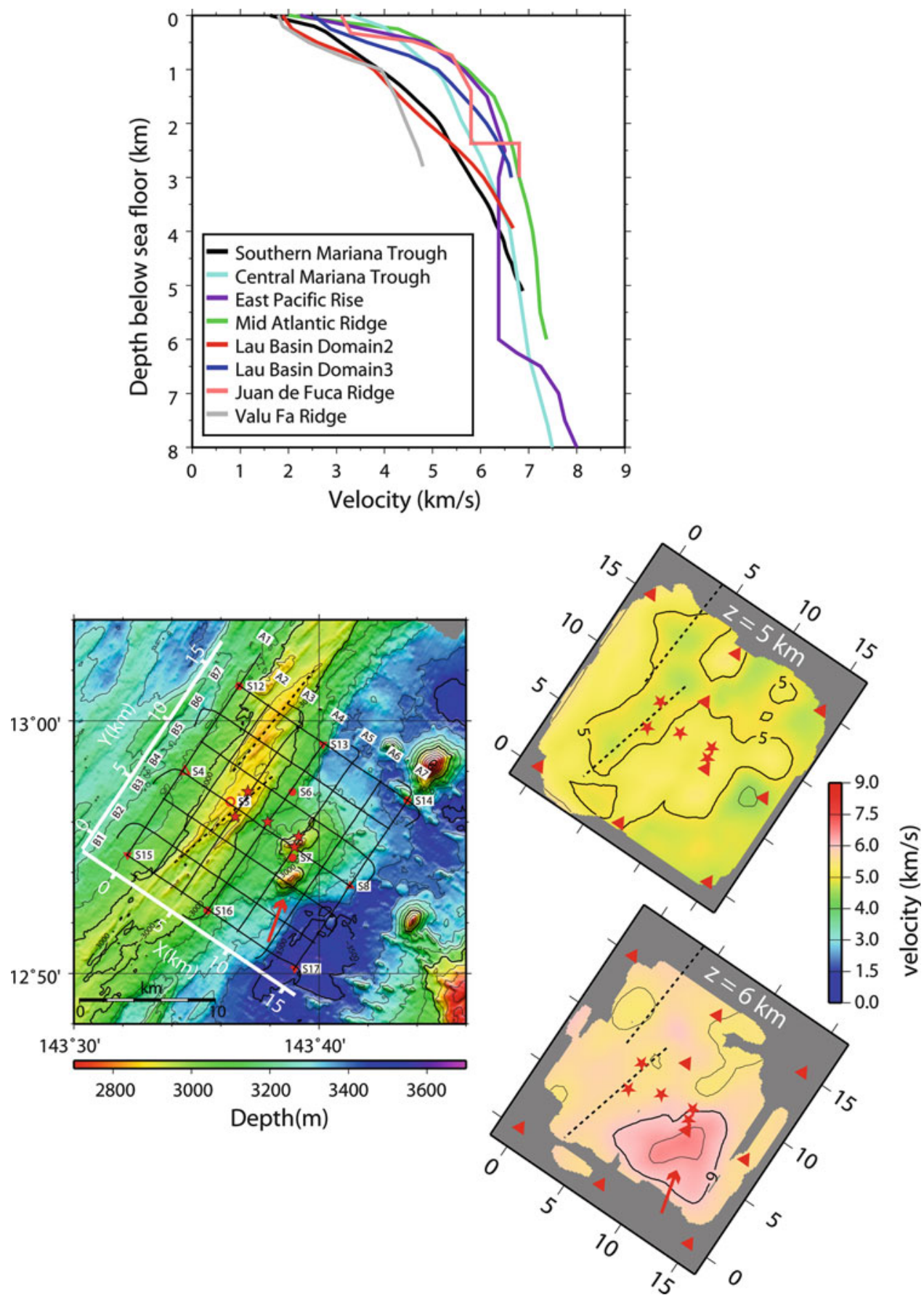

The high-velocity structure with convex upward at the off-axis knoll suggests a thickening of layer 3 beneath the knoll (Sato et al. Chap. 18). They infer that off-axis volcanism once existed there, forming the knoll, and intruded magma became the thickened layer 3 . This off-axis volcanism is very young because the knoll is composed of pillow lavas with minor sediment cover (Kakegawa et al. 2008).

Sato et al. (Chap. 18) found that the relatively thicker layer 2 (thickness about $3 \mathrm{~km}$ ) with lower seismic velocities of the Southern Mariana Trough is similar to those of the
Domain II and the Valu Fa Ridge in the Lau basin (Jacobs et al. 2007; Dunn and Martinez 2011), and they suggest that the upwelling mantle beneath the Southern Mariana Trough spreading axis is influenced by subduction because of the similarity to the Lau Domain II and the Valu Fa Ridge. The Southern Mariana Trough is near the subduction zone and the volcanic arc, and the Lau Domain II and the Valu Fa Ridge are also near the subduction slab and the Tonga volcanic arc. Dunn and Martinez (2011) noted that the Lau Domain II and Valu Fa Ridge are formed by magmas with 
high volatile contents derived from the subducting plate. The upwelling mantle would have low viscosity due to hydration by water from the subducting slab, and the magmas produced would form thicker crust with lower velocities in the Southern Mariana Trough.

\subsection{Hydrothermal Vent Sites}

Five hydrothermal vent sites exist within $5 \mathrm{~km}$ around the spreading axis at $13^{\circ} \mathrm{N}$; two sites on the spreading axis (the Snail and Yamanaka sites), one site at the eastern foot of the axial high (the Archaean site), and two sites on an offaxis knoll (the Pika and Urashima sites). To understand a hydrothermal circulation system, it is important to investigate its heat source, size including pathways, duration, and geological features around the hydrothermal vent site. The crustal structure and the seismicity help to reveal the heat source and the pathways of the hydrothermal circulation related to the geological features (e.g. de Martin et al. 2007). Geophysical surveys using an AUV are effective for near-bottom acoustic and geomagnetic mappings around hydrothermal vent sites. The morphology of the hydrothermal vent site together with dive observation provides us with important constraints on field-scale geological features around the hydrothermal vent site. Near ocean bottom magnetic signatures of active and fossil hydrothermal sites provide information on the size and the duration of the hydrothermal circulation (e.g. Tivey and Johnson 2002). Moreover, near-bottom acoustic and geomagnetic data help to discover a new hydrothermal vent site; a $120 \mathrm{kHz}$ sidescan sonar and a $400 \mathrm{kHz}$ multibeam echo sounder of the AUV Urashima (Kasaya et al. 2011) detected acoustic signals suggesting hydrothermal plumes, and $10 \mathrm{~m}$-scale chimney-like topographic highs within a low magnetization zone, which led to discover the Urashima site (Nakamura et al. 2013). Thus, combination of these geophysical and geological surveys would be important to understand hydrothermal circulation systems.

The information on the heat sources of the hydrothermal sites was provided by the crustal structures. The 3-D seismic velocity structure from the refraction survey in the southern segment of the spreading axis (Sato et al. Chap. 18) covers the area where five hydrothermal vent sites exist. The 3-D seismic velocity structure (Fig. 17.4) shows a low-velocity structure just beneath the third order ridge segment of the spreading axis, suggesting there is some magmatic activity beneath the axis in the form of sheetlike mantle upwellings. These may constitute the hydrothermal heat source at the Snail and Yamanaka sites on the spreading axis. Beneath the off-axis knoll, they have found a high-velocity structure with convex upward that indicates thickening of layer 3 , suggesting the presence of ceased off-axis volcanism there.
The residual heat may contribute the heat for hydrothermal activity at the Pika and Urashima sites on the off-axis knoll. The heat source for the Archaean site at the eastern foot of the axial high is not clear, but it can be constituted by the magmatic activity beneath the spreading axis, because the horizontal distance to the low-velocity zone beneath the axis is only about $1 \mathrm{~km}$ with its depth of $2 \mathrm{~km}$.

The spatial variations of the crustal porosity and the temperature of the fluid within the crust involving a hydrothermal system is estimated using the electrical resistivity structure of the oceanic crust, because the electrical resistivity of the oceanic crust mainly varies with the porosity of the crust and with the connectivity and temperature of the fluid within the crust. The Magnetometric resistivity (MMR) technique using an active (or artificial) electric current source is one of the electromagnetic techniques to reveal the electrical resistivity structure of the uppermost oceanic crust. Matsuno et al. (Chap. 19) carried out a MMR experiment at the Snail and Yamanaka sites on the spreading axis using five ocean bottom magnetometers. The experimental area is almost $4,000 \mathrm{~m}^{2}$ with a focus on the Snail site (Fig. 17.5). Their results of the MMR data analysis show two main features; (1) an optimal 1-D resistivity structure of

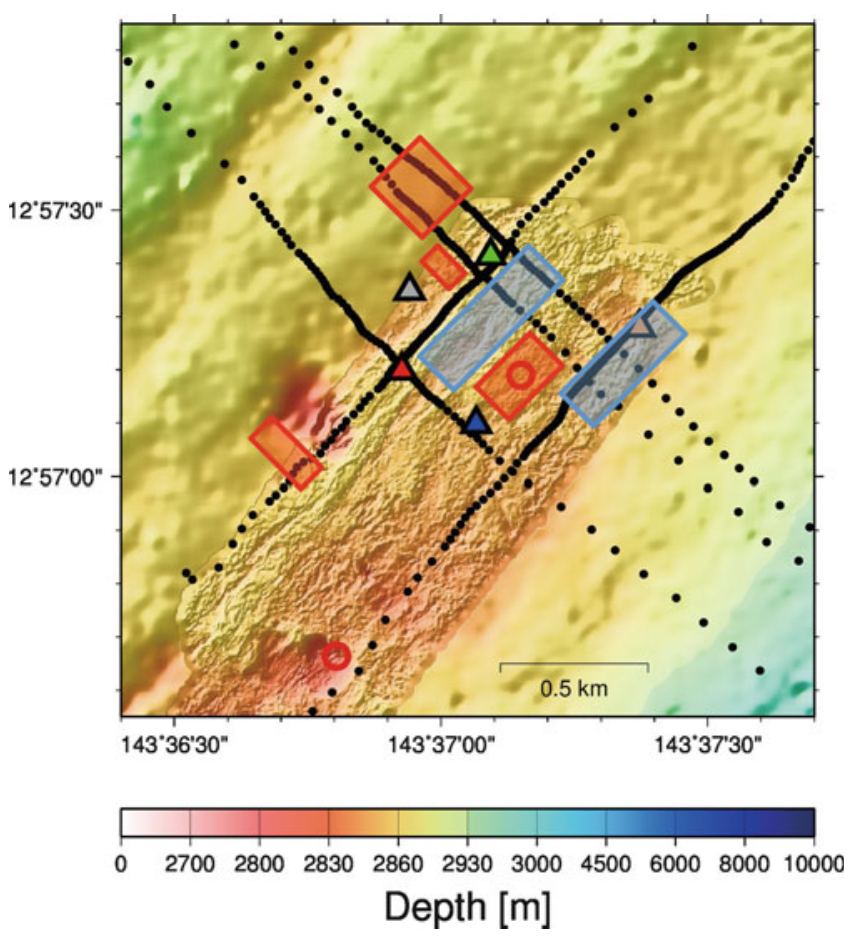

Fig. 17.5 A plan view map of the optimal 3-D resistivity model overlain on the seafloor topography (Matsuno et al. Chap. 19). The red rectangles represent conductive anomalies $(0.56 \Omega-\mathrm{m})$, and the blue rectangles represent resistive anomalies $(56 \Omega-\mathrm{m})$. Locations of the hydrothermal sites (red circles), the transmission points (filled black circles), and the receivers (color triangles) are also shown. The Snail site is located near the center of the map. The location of the survey area is shown in Fig. 17.1 
the uppermost oceanic crust averaged over the experimental area is a two-layer model, which consists of a 5.6 $\Omega$-m upper layer having a $1,500 \mathrm{~m}$ thickness and a $0.1 \Omega$-m underlying half-space, and (2) small optimal 3-D resistivity structures in the optimal 1-D resistivity model includes a conductive anomaly just below the Snail site, two resistive anomalies adjacent to the conductive anomaly on the across-ridge side, and three conductive anomalies away from the Snail site (Fig. 17.5). They interpreted the optimal 1-D resistivity structure using realistic porosity profiles of the uppermost oceanic crust and the Archie's law (Archie 1942); the resistivity of $5.6 \Omega-\mathrm{m}$ at depths ranging from 800 to $1,500 \mathrm{~m}$ suggests the presence of high temperature seawater related to the hydrothermal circulation. The resistivity of $0.1 \Omega-\mathrm{m}$ below $1,500 \mathrm{~m}$ depth may represent a magma mush that is a heat source for the hydrothermal circulation. This low resistivity structure is probably consistent with the low seismic velocity structure beneath the spreading axis (Sato et al., Chap. 18). Further, the 3-D conductive anomaly just below the Snail site suggests the presence of hydrothermal seawater in the shallow crust with its size of approximately $300 \mathrm{~m}^{2}$ area down to $400 \mathrm{~m}$ depth, that is certainly related to the hydrothermal vent.

The style of hydrothermal activity can be investigated by seismicity around the hydrothermal site. A three-month campaign of seismic observations using OBS shows that very low seismicity at the hydrothermal sites (Sato et al. Chap. 18). This result is very different from those of de Martin et al. (2007) and Tolstoy et al. (2008), who found many microearthquakes related to hydrothermal activity. The difference may be because their OBS network had a wider spacing (about $5 \mathrm{~km}$ ) than the earlier networks (about $1-5 \mathrm{~km}$ ), and they examined this possibility by checking the seismicity near an OBS, which was less than $1 \mathrm{~km}$ from the Pika site. They found that it recorded only three events with $\mathrm{S}-\mathrm{P}$ time less than $1 \mathrm{~s}$, indicating that the very low seismicity at the hydrothermal sites is not an artifact of their OBS network, but a real feature in the study area. This very low seismicity suggests that hydrothermal activity here is not related to tectonic stresses.

Geomorphological characterization of field-scale geological features associated with the five hydrothermal vent sites are identified using near-bottom swath mapping data collected by the AUV Urashima and dive observation data acquired by the submersible Shinkai 6500 (Yoshikawa et al. 2012). Their results (Fig. 17.6) indicate differences in geomorphological features between the on-axis sites (the Snail and Yamanaka sites) and the off-axis sites (the Archaean, Pika and Urashima sites), and their explanations are as follows. The Snail and Yamanaka sites on the spreading axis are located adjacent to fissures in the volcanically dominant zone, which is characterized by mounds (height, 5-30 m; diameter, 250-320 m) cut by fissures. The mounds probably result from diking events in a fourth order ridge segment, and the on-axis sites are possibly associated with the diking events followed by the fissures. In contrast to the on-axis sites, the off-axis sites show no evidence of faulting, but undeformed features. The Archaean site at the foot of the axial high is characterized by a single mound (height, 50-100; diameter, 250-300 m), pronounced off-axis lava flows, and the presence of high-amplitude rugged seafloor features; the site is located at the top of the mound. Numerous ridge lines (height, mainly $2-6 \mathrm{~m}$ ) extend radially from the top of the mound, and several chimney-like structures (up to approximately $6 \mathrm{~m}$ high) occur on the top and slopes of the mound. The ridge lines appear to have formed as a result of collapse of the slopes and the top of the mound. The Pika and Urashima sites are located on an off-axis knoll, where is characterized by bumpy seabed textures formed by numerous smaller-scale mounds and ridge lines. The three off-axis hydrothermal sites are composed mainly of breccia assemblages that probably originated from hydrothermal activity with black smoker venting. These geomorphological features suggest that the three off-axis sites were identified as localities created by relatively long-term large-scale hydrothermal activity, as compared with the on-axis sites. Moreover, the undeformed features without any faults suggest that the formation and the sustained activity of the off-axis sites are mainly controlled by an off-axis magma upwelling rather than faulting.

Magnetic signatures of active hydrothermal sites are provided by near ocean bottom geomagnetic surveys, which were conducted around the five hydrothermal vent sites using three fluxgate magnetometers attached on the AUV Urashima. Vector geomagnetic anomalies were obtained based on the method of Isezaki (1986) after subtracting the International Geomagnetic Reference Field (IGRF) model. Vector geomagnetic anomaly field data acquired by the three fluxgate-magnetometers were stacked in order to reduce the short wavelength noises. The geomagnetic anomaly field data are upward continued from the uneven AUV tracks to a constant depth. Then, the equivalent magnetization intensity of the seafloor was estimated using the downward component of the geomagnetic anomaly field, because the observation were performed near the geomagnetic equator and the total intensity of the geomagnetic anomaly field is affected by the strike of a magnetic source, but the downward component of the geomagnetic anomaly field is not. The method of Parker and Huestis (1974) was used for this estimation, and it was modified to adapt for the downward component, because the method is generally used for the total intensity of geomagnetic anomaly field. The magnetic source was assumed to have a constant thickness of $250 \mathrm{~m}$. The result of the crustal magnetization distribution (Fig. 17.6) is well related to the locations of the hydrothermal sites; the distribution of low crustal magnetization 

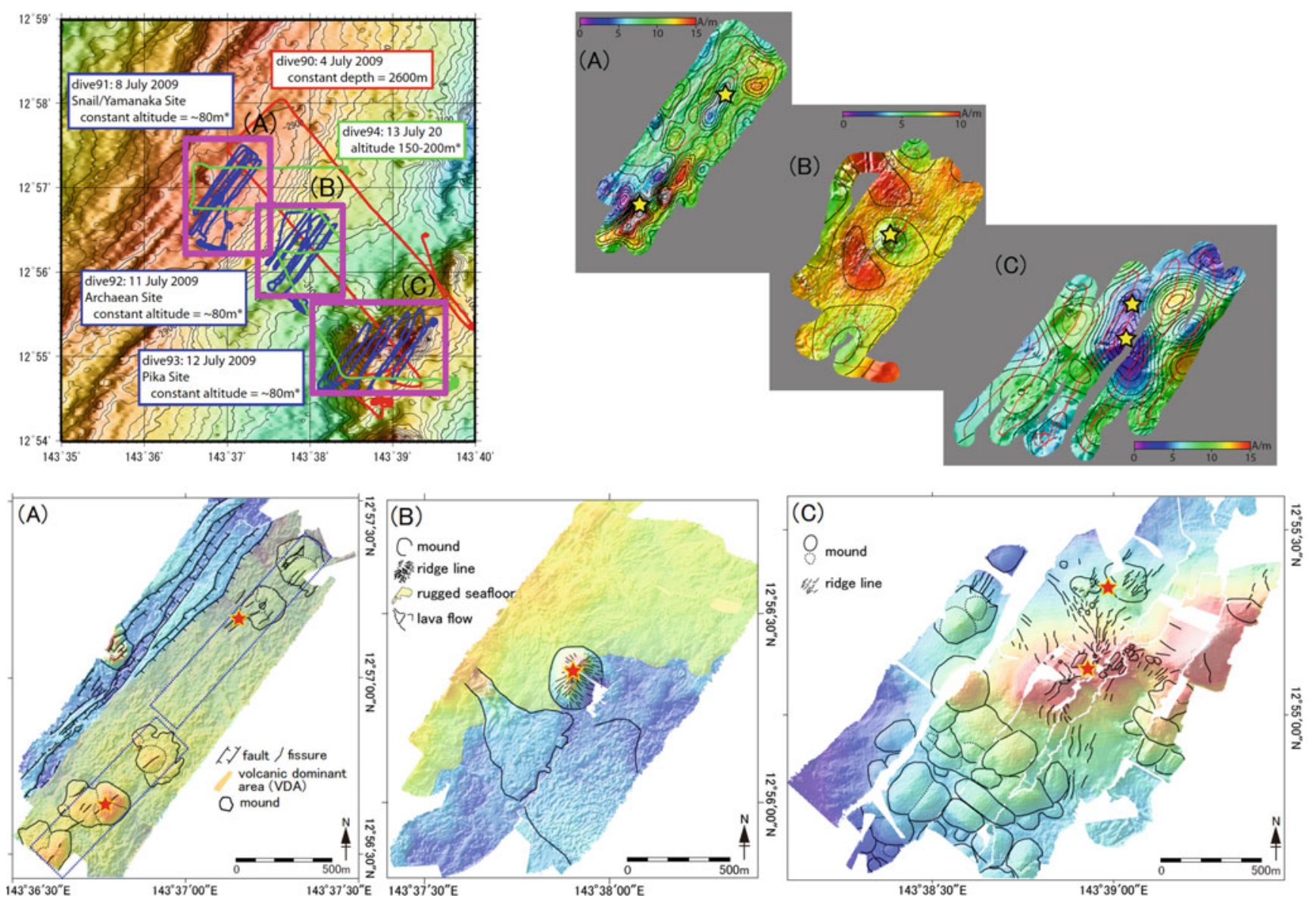

Fig. 17.6 Near-bottom mapping around the five hydrothermal vent sites using the AUV Urashima. Ship tracks of the AUV Urashima (top left), crustal magnetization distribution (top right), and bathymetry with its interpretation by Yoshikawa et al. (2012) (bottom) are shown. The stars indicate the locations of the five hydrothermal vent sites;

coincides mostly with the areas around the hydrothermal sites except for the Yamanaka site on the spreading axis. The low crustal magnetization around the hydrothermal sites most likely indicates a signal that the remanent magnetization of the crust has been reduced through the hydrothermal alternation as suggested by near ocean bottom magnetic signatures of active and fossil hydrothermal sites (e.g. Tivey and Johnson 2002).

\subsection{Results from Rock Analysis}

Volcanic rocks were recovered by the BMS and submersible dives around the five hydrothermal sites in the Southern Mariana Trough back-arc basin (Nakamura et al. Chap. 45). Their new results of geochemical compositions including both major and trace elements are similar to those reported for the southern Mariana area (e.g. Masuda and Fryer, Chap. 21). These volcanic rocks are classified as basaltic andesite to andesite with 55-60\% of $\mathrm{SiO}_{2}$. The trace two sites on the spreading axis (the Snail and Yamanaka sites), one site at the eastern foot of the axial high (the Archaean site), and two sites on an off-axis knoll (the Pika and Urashima sites) are located in the areas $(A),(B)$, and $(C)$, respectively. The location of the survey area is shown in Fig. 17.1

element compositions exhibit enrichment of fluid-mobile elements such as $\mathrm{Cs}, \mathrm{Rb}, \mathrm{Ba}, \mathrm{U}$, and $\mathrm{K}$ with remarkable negative $\mathrm{Nb}$ and $\mathrm{Ta}$ anomaly (Fig. 17.7), suggesting the involvement of subduction components into their parent magmas. These new chemical composition data confirmed the features previously presented for the Southern Mariana Trough by Pearce et al. (2005). They demonstrated that the systematic geochemical mapping for the whole Mariana Trough, and exhibited the distribution of the lithospheric, deep subduction, and shallower subduction components; volcanic glasses from the southern part of the Mariana Trough are influenced by the shallow subduction components while those from $14-15,17$, and $19.5^{\circ} \mathrm{N}$ segments of the spreading axes contain no subduction components and have true MORB compositions. The new chemical composition data (Nakamura et al. Chap. 45) also support the influence by the shallow subduction components.

The new geochemical composition data indicate slightly different features between the on-axis and off-axis hydrothermal sites (Nakamura et al. Chap. 45). All the volcanic 
Fig. 17.7 N-MORB normalized multi element plots for the volcanic rocks from the five hydrothermal sites (Nakamura et al. Chap. 45)

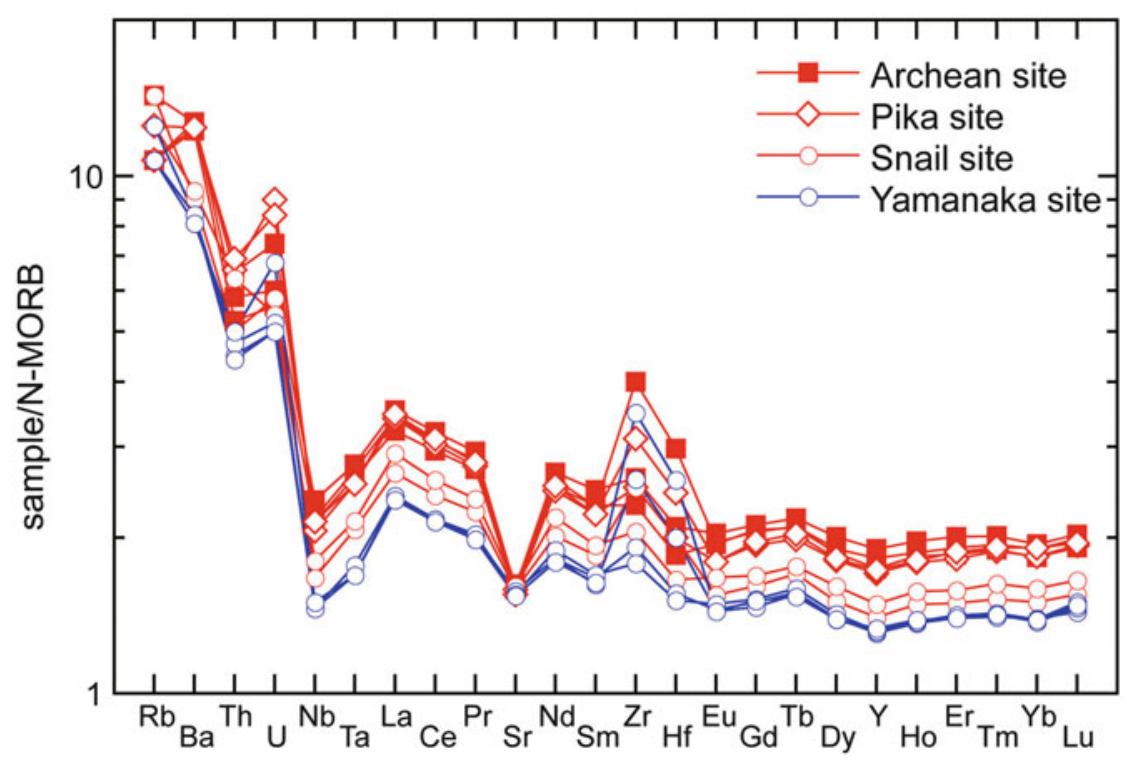

rocks from the on-axis hydrothermal sites are within the basaltic andesite field, whereas the volcanic rocks from the off-axis sites have higher silica abundance and fall in the field of andesite. Major element chemical compositions indicate that their compositional variations can be explained by fractionation except for the Pika site, because the volcanic rocks from the Pika site have clearly distinct fractional trend. They interpreted the basement rocks of the Archaean site as a differentiated product of on-axis magma, whereas those of the Pika site are not directly related to the on-axis magma. The volcanic rocks from the off-axis sites contain relatively higher abundance of trace elements than those from the on-axis sites (Fig. 17.7), which is consistent with the more evolved compositions for the volcanic rocks from the off-axis sites shown in major element compositions.

\subsection{Discussions and Summary}

The results from the geophysical surveys and the volcanic rock samples through the TAIGA Project and those from the previous studies provide strong constraints on the mantle dynamics and the crustal formation at the Southern Mariana Trough back-arc basin; all the results show evidence to support that they are influenced by hydration derived from the subducting slab with accompanying the additional magma supply. The evidence to show dehydration from the subducting slab is only circumstantial evidence, but there is direct evidence to indicate that the additional magma supply and its product of the crust are accompanied by the hydration derived from the subducting slab. The circumstantial evidence to support dehydration from the subducting slab is (1) the shape of the subducting slab, (2) possible low viscosity region in the mantle wedge, and (3) the two-dimensional upper mantle electrical resistivity structure, as listed below:

1. The shape of the subducting slab inferred from a seismic research (Gudmundsson and Sambridge 1998) indicates that the surface of the subducting slab is located at the depth of $120-190 \mathrm{~km}$ beneath the spreading axis in the Southern Mariana Trough back-arc basin (Fig. 17.1). The dehydration from the subducting slab is expected to occur at the depths of 110 and $170 \mathrm{~km}$ (e.g. Tatsumi and Eggins 1995), and the spreading axis is located where the arc volcanic chains are expected to be located. It is contrast to other spreading axes in the Mariana Trough back-arc basin. Since the subducting slab is divided by a near-vertical tear in the slab striking approximately E-W at $14.5^{\circ} \mathrm{N}$ (Miller et al. 2006), the subducting slab on the north side of the tear is not located beneath the spreading axes but beneath the active Mariana Island Arc except for the northern end of the Mariana Trough back-arc basin.

2. The analyses of the bathymetry, geomagnetic anomaly, and MBA data, suggest highly asymmetric seafloor spreading; much faster spreading in the west side of the spreading axis compared to the east side (Seama and Okino, Chap. 20). They proposed that an influence of the low viscosity region in the mantle wedge due to hydration driven by water release from the subducting slab leads to the highly asymmetric seafloor spreading; the low viscosity mantle would preferentially captures the mantle upwelling zone beneath the spreading axis as the spreading axis has been kept in the area closed to the low viscosity region in the mantle wedge, resulting in the highly asymmetric seafloor spreading. Further, they proposed that the different styles of the asymmetric seafloor 
spreading between the northern segment and the southern segment probably show evidence that the influence varies with the depths to the surface of the subducting slab, which is well related to the distance from the low viscosity region. The subducting slab beneath the Southern Mariana Trough back-arc basin is oblique to the spreading axis, and the depth to the surface of the subducting slab beneath the spreading axis is different, 160-190 km for the northern segment and $120-150 \mathrm{~km}$ for the southern segment inferred from a seismic research (Fig. 17.1; Gudmundsson and Sambridge (1998)).

3. Preliminary results of the two-dimensional upper mantle electrical resistivity structure from the MT analysis (Shindo et al. 2012), shows the low resistivity region in the west side. The low resistivity region is probably influenced by hydration driven by water release from the subducting slab; that may result in the additional magma supply to the spreading axis as the low resistivity region may be connected to the intermediate resistivity region under the spreading axis. This result is a contrast to the result from the central Mariana Trough (Matsuno et al. 2010); the two-dimensional upper mantle electrical resistivity structure of the central Mariana Trough shows that the low resistivity region above the subducting slab is not connected to the spreading axis, and the spreading axis is located so far from the subducting slab that there is no evidence to show that the crustal formation has influence of the subducting slab.

The fast spreading morphologic and geophysical characteristics, despite the full spreading rate of about $46 \mathrm{~km} / \mathrm{Myr}$ being categorized as slow spreading, indicate direct evidence of the additional magma supply that is probably accompanied by the hydration derived from the subducting slab. The fast spreading morphologic and geophysical characteristics appear as following: The morphology of the spreading axis of the Southern Mariana Trough back-arc basin shows an axial relief with a broad, smooth cross section, and lacks a deep central graben (Martinez et al. 2000). The crustal thickness variations along the spreading axis estimated using the MBA show larger individual crustal thickness averages $(5.9-6.9 \mathrm{~km})$ and smaller normalized variations in the crustal thickness $(28-30 \mathrm{~m} / \mathrm{km})$, suggesting a sheetlike mantle upwelling with a relatively higher magmatic activity beneath the first-order ridge segments (Kitada et al. 2006). The seismic velocity structure also supports the sheetlike mantle upwelling but it can be subdivided into upwellings beneath the third-order ridge segments; the low-velocity zone beneath the spreading axis, suggesting a warm zone with a chamber of crystal-rich mush, aligns with the third-order ridge segment (Sato et al. Chap. 18). The low electrical resistivity layer below $1,500 \mathrm{~m}$ depth also infers the magma mush beneath the spreading axis (Matsuno et al. Chap. 19). Further, the seismic reflection data show a possible magma chamber reflector beneath the spreading axis (Becker et al. 2010).

The product of the crust that is characterized by the seismic velocity structure and the geochemical composition of the volcanic rocks, shows that the crustal formation at the Southern Mariana Trough back-arc basin is influenced by the hydration derived from the subducting slab. The seismic velocity structure has the thicker layer 2 (thickness about $3 \mathrm{~km}$ ) with lower seismic velocities over the survey area compared with normal mid-ocean ridges and some back-arc spreading ridges, suggesting that the crust is formed by magmas with high volatile contents derived from the subducting plate (Sato et al. Chap. 18). This result is a contrast to the crustal structure of the central Mariana Trough back-arc basin (Takahashi et al. 2008), which is similar to that of the mid-ocean ridges (Fig. 17.4). The geochemical composition data of the volcanic rocks from the Southern Mariana Trough back-arc basin (Nakamura et al. Chap. 45) indicate that the volcanic rocks are classified as basaltic andesite to andesite with $55-60 \%$ of $\mathrm{SiO}_{2}$; that is even higher $\mathrm{SiO}_{2}$ content than those from the Domain II in the Lau basin which was formed by magmas with high volatile contents derived from the subducting plate (Dunn and Martinez 2011). Further, the trace element compositions of the volcanic rocks exhibit enrichment of fluid-mobile elements such as $\mathrm{Cs}, \mathrm{Rb}, \mathrm{Ba}, \mathrm{U}$, and $\mathrm{K}$ with remarkable negative $\mathrm{Nb}$ and $\mathrm{Ta}$ anomaly (Fig. 17.7), suggesting the involvement of the shallow subduction components into their parent magmas (Nakamura et al. Chap. 45).

The results from the geophysical and geological surveys for the five hydrothermal vent sites show different features in the hydrothermal activity between the on-axis hydrothermal sites and the off-axis hydrothermal sites. We propose that the on-axis hydrothermal site is associated with an episodic diking event followed by fissures, and that the duration and size of the on-axis hydrothermal site vary depending on the episodic diking event and on the fissures following. In contrast, the formation of the off-axis hydrothermal sites is closely related to the residual heat from the volcanism rather than tectonic stresses accompanied by faults, and the offaxis hydrothermal activity is for a long period and in a large scale. The two on-axis hydrothermal vent sites (the Snail and Yamanaka sites) are located adjacent to fissures on mounds in the volcanically dominant zone (Yoshikawa et al. 2012), and the heat source for the hydrothermal vent sites is constituted by some magmatic activity beneath the spreading axis in the form of sheetlike mantle upwellings (Sato et al. Chap. 18). Since the mounds probably result from diking events in the fourth order ridge segment, the hydrothermal sites are probably associated with diking events followed by fissures. The present seismicity near the hydrothermal sites is very low (Sato et al. Chap. 18), indicating that the diking is no longer active and that it was probably an 
episodic event. The geomagnetic survey results using the AUV show different characters in the magnetization distribution; clear magnetization low at the Snail site but not at the Yamanaka site (Fig. 17.6). This difference suggests that the activity of the on-axis hydrothermal sites has variety in its duration and size. The activity of the Snail site has continued for a long enough period in a wide enough area (a few hundred meter scale) to reduce the magnetic remanence of the crustal rocks, resulting in the clear low magnetization. Further, the distribution of the low crustal magnetization is elongated parallel to the spreading axis, implying that the hydrothermal activity is tectonically controlled possibly with fissures. On the other hand, the magnetization distribution around the Yamanaka Site including its base mound on the spreading axis shows the high magnetization, suggesting that the mound probably results from a 'recent' diking event and that the hydrothermal activity of the Yamanaka Site should be only for a short period and/or in a small scale possibly due to limited number of the fissures after the diking event. The MMR results (Matsuno et al. Chap. 19) support this difference because the conductive anomaly with its size of approximately $300 \mathrm{~m}^{2}$ area down to $400 \mathrm{~m}$ depth is located only at the Snail site, but not at the Yamanaka site; the conductive anomaly suggests the presence of hydrothermal seawater in the shallow depth, that is certainly related to the hydrothermal vent. Thus, the differences between the Snail and Yamanaka sites suggest that the duration and size of the on-axis hydrothermal site vary depending on the episodic diking event and on the fissures following.

In contrast to the on-axis sites, the formation of the offaxis hydrothermal sites is closely related to the residual heat from the volcanism rather than tectonic stresses followed by faults, and the off-axis hydrothermal activity is for a long period and in a large scale. Geomorphological characterization of field-scale geological features associated with the offaxis sites show no evidence of faulting, but undeformed features (Yoshikawa et al. 2012). The low seismicity near the hydrothermal sites also indicates that there are no faults or fractures related to the hydrothermal activity (Sato et al. Chap. 18), and it is in contrast to the high seismicity of the off-axis TAG hydrothermal site that revealed relations between the hydrothermal system and an active detachment fault (deMartin et al. 2007). The heat source of the Pika and Urashima sites is the residual heat of the ceased off-axis volcanism, which is suggested by the low seismicity and the high-velocity structure that indicates thickening of the layer 3 beneath the off-axis knoll (Sato et al. Chap. 18). The heat source for the Archaean site at the eastern foot of the axial high could be constituted by the magmatic activity beneath the spreading axis. The three off-axis sites were identified as localities created by relatively long-term large-scale hydrothermal activity, because the three off-axis hydrothermal sites are composed mainly of breccia assemblages that probably originated from hydrothermal activity with black smoker venting (Yoshikawa et al. 2012). The geomagnetic survey results using the AUV also support that the hydrothermal activity has been for a long period and in a large scale (a few hundred meter scale) to reduce the magnetic remanence of the crustal rocks, because the magnetization distribution shows clear low magnetization at all the off-axis hydrothermal sites.

In summary, all the evidence we presented leads us to propose our scenario of the mantle dynamics, the crustal formation, and the hydrothermal activity of the Southern Mariana Trough back-arc basin: The subducting slab is located at the depth of $120-190 \mathrm{~km}$ just beneath the spreading axis that is different from most of the other areas in the Mariana Trough back-arc basin. The hydration driven by water release from the subducting slab, which was inferred from the low resistivity region, probably influences the mantle dynamics beneath the spreading axis accompanied by the additional magma supply to the axis. Further, the low viscosity region in the mantle wedge due to hydration may lead to the highly asymmetric seafloor spreading through capturing mantle upwelling zone within the low viscosity mantle. Moreover, this influence of the hydration is also supported by the geochemical compositions of the volcanic rocks and the seismic velocity structure. The geochemical compositions of the volcanic rocks are classified as basaltic andesite to andesite with $55-60 \%$ of $\mathrm{SiO}_{2}$ and their trace element compositions exhibit enrichment of fluid-mobile elements, suggesting the involvement of the shallow subduction component into their parent magma. The seismic velocity structure shows the thicker layer 2 with lower seismic velocities, suggesting the crust is formed by magmas with high volatile contents derived from the subducting slab. Furthermore, the additional magma supply accompanied by the hydration results in the fast spreading morphologic and geophysical characteristics despite the full spreading rate of about $46 \mathrm{~km} / \mathrm{Myr}$ being categorized as a slow spreading. The fast spreading morphologic and geophysical characteristics are the axial relief in morphology, the low electrical resistivity layer and the possible magma chamber reflector beneath the axis, and the sheetlike mantle upwellings beneath the axis suggested by the MBA data and the low-velocity structure. Then, the abundant magma supply leads to the episodic diking events in a fourth order ridge segment supported by the sheetlike mantle upwellings, and to the off-axis volcanism. The two different magmatic activities result in different features between the on-axis and the off-axis hydrothermal sites. The on-axis hydrothermal site is associated with an episodic diking event followed by fissures, and its duration and size vary depending on the episodic diking event and on the fissures following. In contrast, the formation of the off-axis hydrothermal sites is closely related to the residual heat from the volcanism rather 
than tectonic stresses accompanied by faults, and the off-axis hydrothermal activity is for a long period and in a large scale.

Acknowledgments We thank all who assisted in the collection of the data and the samples during the JAMSTEC (Japan Agency for MarineEarth Science and Technology) research cruises and a BMS cruise. This work is supported by the Ministry of Education, Culture, Sports, Science and Technology (MEXT) of Japan for the TAIGA project, Grantin-Aid for Scientific Research on Innovative Areas (20109002). Two anonymous reviewers provided helpful comments. Kumiko Okumura drew some figures and helped to prepare the manuscript. GMT software (Wessel and Smith 1998) was used to create some figures.

Open Access This chapter is distributed under the terms of the Creative Commons Attribution Noncommercial License, which permits any noncommercial use, distribution, and reproduction in any medium, provided the original author(s) and source are credited.

\section{References}

Archie GE (1942) The electrical resistivity log as an aid in determining some reservoir characteristics. J Petrol Technol 5:1-8

Baker ET, Massoth GJ, Nakamura K, Embley RW, de Ronde CEJ, Arculus RJ (2005) Hydrothermal activity on near-arc sections of back-arc ridges: results from the Mariana Trough and Lau Basin. Geochem Geophys Geosyst 6, Q09001. doi:10.1029/ 2005GC000948

Becker NC, Fryer P, Moore GF (2010) Malaguana-Gadao Ridge: identification and implications of a magma chamber reflector in the southern Mariana Trough. Geochem Geophys Geosyst 11: Q04X13. doi:10.1029/2009GC002719

deMartin BJ, Sohn RA, Canales JP, Humphris SE (2007) Kinematics and geometry of active detachment faulting beneath the TransAtlantic Geotraverse (TAG) hydrothermal field on the Mid-Atlantic Ridge. Geology 35:711-714

Dunn RA, Martinez F (2011) Contrasting crustal production and rapid mantle transitions beneath back-arc ridges. Nature 469:198-202

Gudmundsson O, Sambridge M (1998) A regionalized upper mantle (RUM) seismic model. J Geophys Res 103(B4):7121-7136

Isezaki N (1986) A new shipboard three-component magnetometer. Geophysics 51:1992-1998

Jacobs AM, Harding AJ, Kent GM (2007) Axial crustal structure of the Lau back-arc basin from velocity modeling of multichannel seismic data. Earth Planet Sci Lett 259:239-255

Kakegawa T, Utsumi M, Marumo K (2008) Geochemistry of sulfide chimneys and basement pillow lavas at the southern Mariana Trough $\left(12.55^{\circ} \mathrm{N}-12.58^{\circ} \mathrm{N}\right)$. Resour Geol 58:249-266

Kasaya T, Kanamatsu T, Sawa T, Kinosita M, Tukioka S, Yamamoto F (2011) Acoustic images of the submarine fan system of the northern Kumano Basin obtained during the experimental dives of the Deep Sea AUV URASHIMA. Explor Geophys 42:80-87

Kato T, Beavan J, Matsushima T, Kotake Y, Camacho JT, Nakao S (2003) Geodetic evidence of back-arc spreading in the Mariana Trough. Geophys Res Lett 30(12):1625. doi:10.1029/ 2002GL016757
Kitada K, Seama N, Yamazaki T, Nogi Y, Suyehiro K (2006) Distinct regional differences in crustal thickness along the axis of the Mariana Trough, inferred from gravity anomalies. Geochem Geophys Geosyst 7, Q04011. doi:10.1029/2005GC001119

Lin J, Purdy GM, Schouten H, Sempere J-C, Zervas C (1990) Evidence from gravity data for focused magmatic accretion along the MidAtlantic Ridge. Nature 344:627-632

Martinez F, Fryer P, Becker N (2000) Geophysical characteristics of the southern Mariana Trough, $11^{\circ} 50^{\prime} \mathrm{N}-13^{\circ} 40^{\prime} \mathrm{N}$. J Geophys Res 105:16591-16607

Matsuno T, Seama N, Evans R, Chave AD, Baba K, White A, Goto T, Heinson G, Boren G, Yoneda A, Utada H (2010) Upper mantle electrical resistivity structure beneath the central Mariana subduction system. Geochem Geophys Geosyst 11, Q09003. doi:10.1029/ 2010GC003101

Miller MS, Gorbatov A, Kennett BLN (2006) Three-dimensional visualization of a near-vertical slab tear beneath the southern Mariana arc. Geochem Geophys Geosyst 7, Q06012. doi:10.1029/ 2005GC001110

Nakamura K, Toki T, Mochizuki N, Asada M, Ishibashi J, Nogi Y, Yoshikawa S, Miyazaki J, Okino K (2013) Discovery of a new hydrothermal vent based on an underwater, high-resolution geophysical survey. Deep Sea Res I 74:1-10

Parker RL, Huestis SP (1974) The inversion of magnetic anomalies in the presence of topography. J Geophys Res 79:1587-1593

Pearce JA, Stern RJ, Bloomer SH, Fryer P (2005) Geochemical mapping of the Mariana arc-basin system: Implications for the nature and distribution of subduction components. Geochem Geophys Geosyst 6, Q07006. doi:10.1029/2004GC000895

Shindo H, Seama N, Matsuno T, Shibata Y, Kimura M, Nogi Y, Okino $\mathrm{K}$ (2012) Electrical resistivity structure of the upper mantle in the Southern Mariana Trough. Abstract T51D-2612 presented at 2012 Fall Meeting, AGU, San Francisco, 3-7 Dec

Takahashi N, Kodaira S, Tatsumi Y, Kaneda Y, Suyehiro K (2008) Structure and growth of the Izu-Bonin-Mariana arc crust: 1. Seismic constraint on crust and mantle structure of the Mariana arc-back-arc system. J Geophys Res 113:B01104. doi:10.1029/2007JB005120

Tatsumi Y, Eggins S (1995) Subduction zone magmatism. Blackwell, Boston

Tivey MA, Johnson HP (2002) Crustal magnetization reveals subsurface structure of Juan de Fuca Ridge hydrothermal fields. Geology 30:979-982. doi:10.1130/0091-7613(2002)030<0979:CMRSSO > 2.0.CO;2

Tolstoy M, Waldhauser F, Bohnenstiehl DR, Weekly RT, Kim WY (2008) Seismic identification of along-axis hydrothermal flow on the East Pacific Rise. Nature 451:181-184

Urabe T, Ishibashi J, Maruyama A, Marumo K, Seama N, Utsumi M (2004) Discovery and drilling of on- and off-axis hydrothermal sites in backarc spreading center of southern Mariana Trough, western Pacific. Eos Trans AGU 85(47). Fall Meet. Suppl., Abstract V44A-03

Wessel P, Smith WH (1998) New, improved version of the Generic Mapping Tools released. EOS Trans Am Geophys Un 79:579

Yamazaki T, Seama N, Okino K, Kitada K, Joshima M, Oda H, Naka J (2003) Spreading process of the northern Mariana Trough: riftingspreading transition at $22^{\circ} \mathrm{N}$. Geochem Geophys Geosyst 4(9): 1075 . doi:10.1029/2002GC000492

Yoshikawa S, Okino K, Asada M (2012) Geomorphological variations at hydrothermal sites in the southern Mariana Trough: Relationship between hydrothermal activity and topographic characteristics. Mar Geol 303-306:172-182 